\title{
Sociocultural Variations of Coping Strategies for Sleep Difficulties in Couple Relationships in Canada and Brazil
}

\author{
Taís Araújo, Ph.D. ${ }^{\star 1,2,5}$, Alexandre Lemyre, M.A. ${ }^{1,2}$, Annie Vallières, Ph.D. ${ }^{1,2,3,4}$, Yvan Leanza, Ph.D. ${ }^{1,5,6,7}$ \\ 1École de psychologie, Université Laval, Québec, QC, Canada \\ 'Laboratoire Psycho | Socio | Culturel du sommeil, Université Laval, Québec, QC, Canada \\ ${ }^{3}$ Centre de recherche CERVO, Québec, QC, Canada \\ ${ }^{4}$ Centre de recherche du CHU de Québec - Université Laval, Québec, QC, Canada \\ ${ }^{5}$ Laboratoire Psychologie et Cultures, Université Laval, Québec, QC, Canada \\ ${ }^{6}$ Centre interuniversitaire d'études sur les lettres, les arts et les traditions - CÉLAT, Université Laval, Québec, QC, Canada \\ ${ }^{7}$ Centre intégré universitaire de santé et de services sociaux (CIUSSS) du Centre Ouest de l'Île de Montréal - Centre SHERPA, équipe METISS, Montréal, QC, Canada
}

\section{ABSTRACT}

The couple relationship (marriage/cohabitation) is, for most adults, the primary social context of sleep. Although there is a growing literature on couples' sleep, no qualitative cross-cultural study on this topic has yet been published. The aim of the present study was to explore the strategies used by adult couples with sleep difficulties from two different cultures, as well as the potential sociocultural variations related to these strategies. Six couples in Quebec City (Canada) and five couples in Fortaleza (Brazil), of which one or both partners experienced sleep difficulties, were recruited. Participants completed the Pittsburgh Sleep Quality Index, the Dyadic Adjustment Scale, and gave open-ended reports regarding their sleep every morning for a week. They also took part in an in-depth semistructured interview for couples. The interviews were transcribed verbatim and analyzed using the Critical Phenomenological Method. The participants' strategies in the face of sleep difficulties fell into three modalities: individual, common and shared, and common and independent. Within these modalities, seven strategies were identified in both research sites: body and mind relaxation before sleep, stress reduction in daily life, reduction of sleep performance anxiety, respect of the partner's sleep, intervention or drug use to induce sleep or to reduce diurnal sleepiness, diet monitoring, and naps. The present study reveals that the coping strategies used by partners are related not only to the individual, but can be shared, and are closely related to the sociocultural, economic and environmental contexts of their respective countries.

Keywords: Couples, cross-cultural, phenomenology, content analysis

\section{INTRODUCTION}

A third of our life is spent sleeping (Martin, 2005). Contrary to popular beliefs, sleep goes far beyond a

\footnotetext{
*Correspondence: tais.araujo.1@ulaval.ca

Taís Araújo, Ph.D., Psy., École de psychologie, Université Laval, Pavillon

Félix-Antoine Savard, Bureau 1310, 2325 rue des Bibliothèques

Québec (QC), G1V 0A6, CANADA

Phone: +1 4186562131 \# 5020. Fax: +1 4186563646
}

Received: 01 May 2018 Accepted: 03 July 2018

\section{Sleep and Hypnosis \\ Journal homepage: \\ www.sleepandhypnosis.org \\ ISSN: 2458-9101 (Online)}

natural, biological, and individual behaviour fundamental to health and wellbeing. Indeed, sleep is increasingly recognized as a "complex (learned) behaviour or practice that displays a high degree of socio-cultural plasticity or variability" (Williams, 2005, p. 3). For most adults, the couple relationship (marriage/cohabitation) is the primary social context of sleep, which in the lifespan of the couple, includes thousands of shared sleep episodes (National Sleep Foundation, 2010; Rosenblatt, 2006).

In recent years, there has been a growing interest in couples' sleep. Holliday and Troxel (2017) recently published a systematic review of the link between dimensions of relationship functioning and sleep, which 
was an update from a previous review (Troxel, Robles, Hall, \& Buysse, 2007). The authors proposed an integrative model in which dimensions of the relationship (i.e. support/conflict, intimacy/avoidance, security/ withdrawal, closeness/vigilance, and positive emotions/ negative emotions) and sleep variables (i.e. sleep quality, sleep continuity, sleep architecture, and sleep disorders) interact. According to this model, functional dimensions of the relationship, and sleep variables could influence each other through psychological and cognitive mechanisms (e.g., depression, anxiety, problem solving skills), physiological mechanisms (e.g., HPA axis dysregulation, circadian rhythms) and sleep related behaviours (e.g., sleep hygiene, adherence to sleep treatment). It should be noted that in these two reviews (Holliday \& Troxel, 2017; Troxel et al., 2007), all but one selected study (Ellis, Deary, \& Troxel, 2015) used quantitative methods.

Qualitative studies have shed light on different aspects of couples' sleep. Qualitative methods (e.g., focus group, semistructured interviews) offer a detailed and nuanced perspective on human experience by generating novel, individualized, and more in-depth data (Araújo, Jarrin, Leanza, Vallières, \& Morin, 2017; Marshall \& Rossman, 2016). Hislop (2007) discussed the negotiation of the sleeping environment, including the side of the bed used by each partner, the material used to sleep (mattress/ pillows) and the partners' sleep routines. According to these authors "given the differences in preferences, needs, expectations, behaviours and roles during the night, the propensity for disruption and embarrassment is high" (Hislop, 2007). Another important matter for negotiation in many couples is the care provided to children at night. According to Venn, Arber, Meadows, and Hislop (2008), mothers are typically more involved in the care provided to young children during the night, while the fathers assume a role of protector as their children grow up and become more autonomous. The tasks and apprehensions specific to these gendered roles often result in sleep disruptions for both partners (Venn et al., 2008). Negotiations in the context of bed sharing can also concern behaviours that disturb the partner's sleep, for instance, snoring. Snoring is typically perceived as a "masculine" behaviour: it carries little or no stigma for men, but it is an important source of embarrassment for women. The main strategies used to cope with snoring include passivity, prodding or nudging, and relocation (Venn, 2007). The need to sleep apart from one's partner has also been reported by individuals suffering from sleep apnea (Reishtein et al., 2006). Finally, Elfström et al. (2012) interviewed 25 partners of patients treated for sleep apnea in order to identify situations that could influence their support for the partner during treatment. Adverse effects (e.g., problems with the mask), limited effects (e.g., continuing symptoms), and psychosocial problems (e.g., shame) affected the partners' support negatively, while a well-functioning treatment (e.g., easy manageable routines), improvements (e.g., improved sleep) and high motivation (e.g., positive attitude toward the treatment) affected the partners' support positively.

Despite increasing efforts to study couples' sleep, the role of social and cultural factors has not yet received significant attention. Of the 47 articles discussed in the two major reviews on couples' sleep (Holliday \& Troxel, 2017; Troxel et al., 2007), only two (Lalley-Chareczko et al., 2015; Troxel, Buysse, Hall, \& Matthews, 2009) reported data pertaining to the influence of ethnicity. LalleyChareczko et al. (2015) found that having experienced physical violence or unwanted sex with an intimate partner in the preceding year was associated with poorer sleep in Caucasians and Asians, while it was associated with better sleep in Hispanics; no association was found between these variables for African Americans. According to Troxel et al. (2009), among midlife married women, marital happiness is associated with better sleep in Caucasians, while it is not associated with sleep in African Americans. No study has analyzed couples' sleep across countries, although differences would be expected, since every society has its norms concerning sleep (Arber, Meadows, \& Venn, 2012).

There is also a lack of research on the strategies used by couples to cope with the sleep difficulties of either partner. Indeed, one might have expected to find documentation on this subject considering that sleep problems are highly prevalent (Morin \& Jarrin, 2013), and that poor sleep can impact health, individual and 
public security, and economy (Luyster, Strollo Jr, Zee, \& Walsh, 2012; Rosekind \& Gregory, 2010). Williams, Coveney, and Gabe (2013) even stated that "sleep problems are endemic in contemporary society given the transition to a 24/7 global age and the advent of an on-line digital culture to keep us from our beds [...]" (p. 41). It is particularly interesting that coping strategies used by couples could simultaneously influence the partners' sleep difficulties and the quality of the couple relationship.

The present study aimed to take a first step toward a cross-cultural analysis of couples' sleep, while exploring an important topic - coping strategies - for which no information is available. More precisely, the aim of this study was to explore the strategies used to cope with sleep difficulties by adult couples from Quebec (Canada) and Fortaleza (Brazil), as well as the potential sociocultural variations related to these strategies.

\section{METHOD}

\section{Sample}

Six couples in Quebec City (Canada) and five couples in Fortaleza (Brazil), of which one or both partners experienced sleep difficulties were recruited between October 2010 and March 2011 by the main researcher (T.A.). This sample size is in accordance with the recommendations for qualitative research, and for phenomenological studies to reach saturation (Creswell, 1998).

Inclusion and exclusion criteria were the same for both research sites. Inclusion criteria were (a) to have Canadian or Brazilian origin; (b) to be between 24 and 50 years of age; (c) to have lived together as a couple for at least two years; (d) to present a subjective complaint of sleep difficulties (either or both partners); and (e) to agree to participate together in the study. The exclusion criteria were chosen based on their potential to disturb the partners' sleep: (a) to have one or more dependent children at home; (b) to be diagnosed with a chronic disease; (c) to work at night; (d) to be pregnant; and/or (e) to experience menopause.

\section{Procedure}

Participant eligibility was ascertained by a telephone interview using a questionnaire containing eight closedended questions. Eligible participants attended two meetings one week apart. Firstly, they were invited to complete two self-report questionnaires (Pittsburgh Sleep Quality Index/PSQl; Dyadic Adjustment Scale-16/ DAS-16) and, secondly, to take part in an in-depth semistructured interview for couples. During the week between the two meetings, partners wrote individual and open-ended reports about their night of sleep upon awakening. An informed consent form and confidentiality agreement were signed by each participant prior their participation in the study, and contact coordinates for help resources were given. Ethical approval of the current study was obtained from the Université Laval ethics committee (\# 2010-060 A-1/13-09-2010).

Recruitment for this study was different for the two research sites. In Quebec City (Canada), the recruitment took place in fall 2010 (October-November) and winter 2011 (February-March). An e-mail invitation to the study was sent on three occasions to all students and employees of Université Laval. Ads were displayed on the campus and in public places, such as convenience stores and bus stops. In this city, 25 couples responded to the invitation, and 11 were eligible. Among them, five decided not to participate before the second meeting was completed. The meetings took place in the consultation service of the École de psychologie. Saturation was reached at the sixth interview. These participants received a $40 \$$ certificate for a dinner in a restaurant. In Fortaleza (Brazil), the recruitment took place in summer 2011 (JanuaryFebruary), during the university holidays, making it impossible to replicate the procedure used in Quebec City. Instead, the main researcher (T.A.) made verbal invitations during her day-to-day encounters and sent a written invitation to her professional contact lists. In this city, 25 couples responded to the invitation and six were eligible. The meetings took place in the participants' home since they preferred this, despite access to a room in a psychological clinic. Saturation was reached at the fifth interview. No monetary compensation was given to these participants. All interviews were performed by the main 
researcher (T.A.) who is bicultural, bilingual and a licensed psychologist in both countries (Canada and Brazil).

\section{Instruments}

Questionnaires. The Pittsburgh Sleep Quality Index (PSQl; Buysse, Reynolds, Monk, Berman, \& Kupfer, 1989) is a 19-item questionnaire that assesses sleep quality under seven components over the preceding month. The total score varies between "0" and "21". A score over 5 indicates a perception of poor sleep quality. The PSQI has been validated in French (Blais, Gendron, Mimeault, \& Morin, 1997) and in Portuguese (Bertolazi et al., 2011), and possesses adequate psychometric qualities in both languages.

The Dyadic Adjustment Scale-16 (DAS-16) evaluates the degree of agreement and the quality of marital interactions. Items are assessed on a Likert scale from "0" (never agree/extremely unhappy) to " 5 " (always agree/ extremely happy). A total score of 50 and over indicates an adequate adaptation in the couple relationship. The DAS-16 has been validated in French (Antoine, Christophe, \& Nandrino, 2008), but not in Portuguese, although the original 32 item version (DAS-32; Spanier, 1976) has been translated to Portuguese and used in many Brazilian studies (e.g. Hernandez, 2008).

In-depth semistructured interview. The Phenomenological Interview for Couples (PIC) is an indepth semistructured interview lasting 40 to 60 minutes. The PIC's initial question was "What does the term "sleep difficulties" mean to you in your everyday life?" If needed, additional questions were asked, including the following: "Do you use strategies to cope with your sleep difficulties in your couple relationship? Which strategies?" Participants were informed that they could stop the interview at any time without prejudice. A pilot interview was performed with a couple from Quebec City to adjust interview time and the clarity of questions.

Sleep free reports. Sleep Free Reports (SFR; Vercelli, 2006) were completed upon awakening for seven days. Participants were told only to write individual and open-ended reports about their previous night's sleep without sharing information between them. The style, format, and descriptive scope of the data were left to their discretion.

\section{Qualitative Data Analysis}

The PIC were audio-taped and transcribed verbatim. They were conducted and analyzed using the Critical Phenomenological Method (CPM), "(...) proposed by Giorgi (1985) and adapted by Moreira (2004) (Table 1). All four steps were performed by the main researcher (T.A.). The CPM was chosen as it depicts the life world of participants from the description of the multiple contours (e.g., socioeconomic, politic, cultural) in which they are deeply intertwined day by day.

Sample quotations from the original data are presented in the Results section. They were selected mainly from the interviews, but some quotations were also from the SFR. All are presented here in English, but they were originally reported in French or in Portuguese. Translation from French/Portuguese to English was performed by the first author (T.A.) and second author (A.L.), and revised by a professional translator who is a native English speaker (J.E.).

\section{RESULTS}

\section{Participants' characteristics}

The participants' ages varied between 24 and 35 years in Quebec City and between 26 and 47 years in Fortaleza. Those from Quebec City were graduates and employees $(n=8)$ or undergraduate/postgraduate students $(n=4)$, while those from Fortaleza were all graduates and employees, except for one participant who abandoned his bachelor's degree before graduation. Five of the six couples from Quebec City were in common-law union, while all couples from Fortaleza were married. The average relationship duration in Quebec City and Fortaleza was 4.4 and 7.4 years, respectively.

Ten out of 12 participants ( 6 women/4 men) in Quebec City and seven out of 10 participants (3 women/4 men) in Fortaleza had subjective complaints of sleep difficulties. However, seven out of 12 participants in 
Table 1. The four steps for a phenomenological analysis based on the Critical Phenomenological Method

\begin{tabular}{ll}
\hline Steps & Procedure \\
\hline Step 1 & The transcripts are read several times. \\
Step 2 & $\begin{array}{l}\text { The texts are defined in "movements" according to their "tones" (i.e., when a change in themes occurred), through a } \\
\text { process of phenomenological reduction. The researcher's knowledge, presuppositions, and suspicions that could bias her } \\
\text { perception of the phenomenon are identified and put into "brackets". }\end{array}$ \\
Step 3 & $\begin{array}{l}\text { A qualitative content analysis of each "movement" is performed in order to analyze their emergent meanings, and to } \\
\text { group the statements, citations, and themes into main categories. These categories are developed, modified, or sorted } \\
\text { (groupings of categories) during the descriptive and analytical process. } \\
\text { Step } 4\end{array} \quad \begin{array}{l}\text { The researcher - no longer in the "bracketing" process - tracks the original qualitative research question, then connect it } \\
\text { with the results obtained and the theoretical framework adopted in the study. }\end{array}$ \\
\end{tabular}

Quebec City (5 women/2 men) and five out of 10 participants in Fortaleza (2 women/3 men) presented a poor sleep quality (PSQI score $>5$ ) in the month prior to their participation in the study. Women showed the most sleep difficulties $(\mathrm{N}=9)$ and the presence of a poor subjective sleep quality ( $=7$ ). In Quebec City, all but one participants indicated at least a level of "satisfying relationship" (DAS-16 score > 50.2), while most participants in Fortaleza reported a "very satisfying relationship" (DAS-16 score > 61.2) (see Table 2).

\section{Phenomenological analysis results}

The strategies reported by the participants aimed to cope with their own sleep difficulties or those of their partner. They were also used to reduce the consequences of poor sleep (e.g., fatigue, daytime sleepiness,

Table 2. Subjective complaint of sleep difficulties, score of sleep difficulties and score of marital adjustment

\begin{tabular}{|c|c|c|c|c|}
\hline & & $\begin{array}{l}\text { Subjective complaint } \\
\text { of sleep difficulties }\end{array}$ & PSQI score ${ }^{b}$ & DAS-16 score ${ }^{c}$ \\
\hline & & \multicolumn{3}{|c|}{ Quebec City (Canada) } \\
\hline \multicolumn{5}{|c|}{ Couple } \\
\hline \multirow[t]{2}{*}{ \# 4} & $\left(W^{\mathrm{a}}\right)$ & yes & 10 & 51 \\
\hline & $\left(M^{a}\right)$ & yes & 5 & 59 \\
\hline \multirow[t]{2}{*}{ \# 5} & $(W)$ & yes & 9 & 59 \\
\hline & (M) & yes & 8 & 58 \\
\hline \multirow[t]{2}{*}{ \# 6} & (W) & yes & 16 & 55 \\
\hline & (M) & yes & 7 & 26 \\
\hline \multirow[t]{2}{*}{ \# 9} & $(W)$ & yes & 10 & 64 \\
\hline & $(M)$ & no & 5 & 51 \\
\hline \multirow[t]{2}{*}{ \# 11} & $(W)$ & yes & 7 & 61 \\
\hline & (M) & no & 2 & 57 \\
\hline \multirow[t]{3}{*}{ \# 13} & $(W)$ & yes & 4 & 67 \\
\hline & (M) & yes & 4 & 63 \\
\hline & & \multicolumn{3}{|c|}{ Fortaleza (Brazil) } \\
\hline \multicolumn{5}{|c|}{ Couple } \\
\hline \multirow[t]{2}{*}{ \#2 } & $(W)$ & yes & 10 & 67 \\
\hline & $(\mathrm{M})$ & no & 5 & 75 \\
\hline \multirow[t]{2}{*}{$\# 3$} & $(\mathrm{~W})$ & yes & 4 & 47 \\
\hline & (M) & yes & 5 & 57 \\
\hline \multirow[t]{2}{*}{$\# 4$} & $(\mathrm{~W})$ & no & 3 & 64 \\
\hline & (M) & yes & 17 & 65 \\
\hline \multirow[t]{2}{*}{$\# 5$} & $(W)$ & no & 2 & 74 \\
\hline & (M) & yes & 8 & 55 \\
\hline \multirow[t]{2}{*}{ \# 6} & (W) & yes & 10 & 65 \\
\hline & (M) & yes & 10 & 63 \\
\hline
\end{tabular}

Notes. a. $W=$ woman, $M=$ man; b. Scores PSQI > 5 = poor sleep quality; c. Scores DAS-16: 0 - 38.65 = unsatisfactory relationship, 39.2 - $49.65=$ slightly unsatisfactory relationship, $50.2-60.65$ = satisfying relationship, $61.2-78.25$ = very satisfying relationship. 
Table 3. Strategies used to cope with sleep difficulties

\begin{tabular}{|c|c|c|}
\hline Modalities & Strategies & Examples/Verbatim \\
\hline \multirow[t]{7}{*}{ Individual } & $\begin{array}{l}\text { body and mind relaxation } \\
\text { before sleep }\end{array}$ & $\begin{array}{l}\text { "to take a warm bath, to drink warm milk" } \\
\text { "to visualise or imagine" oneself in a pleasant place before falling asleep } \\
\text { "to watch television" } \\
\text { "to drink chamomile tea" } \\
\text { "to read before sleep" }\end{array}$ \\
\hline & stress reduction in daily life & $\begin{array}{l}\text { "to better manage everyday life stress" } \\
\text { "to integrate Yoga in my life, thus to try to do things that will decrease my stress } \\
\text { level in general" } \\
\text { "to return in therapy"; "to consult a psychologist" to better manage stress, or } \\
\text { difficult situations in everyday life and therefore, being able to sleep better } \\
\text { "to let go about work" } \\
\text { "to try to calm down in the evening, and not to think about work" }\end{array}$ \\
\hline & $\begin{array}{l}\text { reduction of sleep performance } \\
\text { anxiety }\end{array}$ & $\begin{array}{l}\text { "to do (more) physical activities"; "to fatigue my body", by exercising } \\
\text { "to sleep with ear plugs", to mute the sounds of the environment that prevent } \\
\text { sleep } \\
\text { "not to check the time when waking up at night" to avoid increasing anxiety }\end{array}$ \\
\hline & respect of the partner's sleep & $\begin{array}{l}\text { "to let the door ajar... it is less likely to wake me up", when the partner returns } \\
\text { home late } \\
\text { "to close the door on tip-toes" } \\
\text { "to watch television at night in a room other than the master bedroom" to avoid } \\
\text { disturbing the partners' sleep } \\
\text { to have comfortable blankets in sufficient quantity for both partners } \\
\text { to adopt an "understanding" attitude toward the partner, who suffers more from } \\
\text { sleep difficulties } \\
\text { "not to talk to him/her when waking up in the middle of the night" }\end{array}$ \\
\hline & $\begin{array}{l}\text { intervention / drug use to } \\
\text { induce sleep or to reduce } \\
\text { diurnal sleepiness }\end{array}$ & $\begin{array}{l}\text { "to go to bed sooner" to be in better shape the next day } \\
\text { "to nudge, to turn him/her aside" when he/she is snoring } \\
\text { to take "medication", "melatonin", "valerian", "alcohol" (in the evening, with or } \\
\text { without significant others) to facilitate sleep } \\
\text { "to stay up" in order to stay awake during the day } \\
\text { "to drink coffee" in order to cope with diurnal sleepiness }\end{array}$ \\
\hline & diet monitoring & "not to eat a heavy meal before going to sleep" \\
\hline & naps & "napping" \\
\hline \multirow[t]{5}{*}{$\begin{array}{l}\text { Common and } \\
\text { shared }\end{array}$} & $\begin{array}{l}\text { body and mind relaxation } \\
\text { before sleep }\end{array}$ & $\begin{array}{l}\text { "to be together (as a couple) before going to sleep and to make the break } \\
\text { between daytime and sleep time" } \\
\text { "to walk together during the evening" } \\
\text { "not to watch television right before going to sleep" } \\
\text { "to relax a little bit before going to sleep" } \\
\text { "massages" } \\
\text { "to calm down, to relax together" }\end{array}$ \\
\hline & stress reduction in daily life & $\begin{array}{l}\text { "to reduce the stress that we can experience in different ways" } \\
\text { "to resolve couples' issues before sleeping" } \\
\text { "to change our conversations, to change our way of looking at things in the } \\
\text { evening when we come back [from work]... to establish a law of 'no work' at } \\
\text { home... to start thinking about talking of other things..." }\end{array}$ \\
\hline & respect of the partner's sleep & $\begin{array}{l}\text { "to make sure to say each other what we have to say, so that when we are in } \\
\text { bed, we can lie down to sleep" } \\
\text { Be aware of "not to talk in bed" for too long and loose hours of sleep }\end{array}$ \\
\hline & $\begin{array}{l}\text { intervention / drug use to sleep } \\
\text { or to reduce diurnal sleepiness }\end{array}$ & $\begin{array}{l}\text { "going to bed sooner" together } \\
\text { "to always keep the window open... even in winter, to always let air circulate" } \\
\text { "to improve our mattress quality"; "to have a comfortable mattress" } \\
\text { "to have a darker room for the morning light" } \\
\text { "to relearn to be accustomed to each other" }\end{array}$ \\
\hline & diet monitoring & "not to eat a heavy meal before going to sleep" \\
\hline \multirow[t]{3}{*}{$\begin{array}{l}\text { Common and } \\
\text { independent }\end{array}$} & $\begin{array}{l}\text { intervention / drug use to sleep } \\
\text { or to reduce diurnal sleepiness }\end{array}$ & $\begin{array}{l}\text { "to wet my face" in order to cope with diurnal sleepiness } \\
\text { "to sleep in separate rooms" } \\
\text { "to wear ear plugs to sleep" }\end{array}$ \\
\hline & diet monitoring & "not to eat a heavy meal before going to sleep" \\
\hline & naps & "naps" \\
\hline
\end{tabular}


moodiness) in daily life or nourish the partners' relationship. More specifically, the participants' strategies fell into three modalities: (a) individual: each partner adopted his/her own strategies; (b) common and shared: the two partners adopted the same strategies together and used them at the same time of the day or night; (c) common and independent: the two partners adopted the same strategies together, but used them independently from each other at different times of the day or night. Within these modalities, seven strategies were identified in both research sites: (a) body and mind relaxation before sleep; (b) stress reduction in daily life; (c) reduction of sleep performance anxiety; $(d)$ respect of the partner's sleep; (e) intervention or drug use to induce sleep or to reduce diurnal sleepiness; $(f)$ diet monitoring; and (g) naps (see Table 3).

The strategies were usually oriented by the subjective perceptions of the partner who was suffering from sleep difficulties. These perceptions concerned sleep difficulty severity, the ability to tolerate the negative consequences in daily life, and the degree of trust in the capacity of healthcare professionals to address sleep problems. Furthermore, participants reported that their strategies could be transmitted and maintained through life cycles (trans generational knowledge) or come from family and friends' suggestions (tips). These strategies could be beneficial, or not, for the sleep problems experienced.

\section{Differences between strategies adopted in} Quebec City and in Fortaleza. Couples from Quebec City were more prone to use common and shared strategies focused on both partners:

Couple 5 (Canada) - Woman: "We are glad that each of us does our part, take turns to help the other feel better... We try strategies together, we see that we both make efforts - Man: Yes - And, it is positive because we try to solve the problem together..."

Couples from Fortaleza adopted more individual strategies oriented toward themselves or their partner. For instance, in two couples from Fortaleza (Couple 2/ Couple 3), the male partners used individual strategies for the benefit of their wives. These strategies were usually proactive and compassionate actions, and employed after complaints of poor day-to-day functioning by the partner who was suffering from sleep difficulties:

Couple 2 (Brazil) - Woman: "...many times, well, after dinner, he washes the dishes cause like that... he says: 'don't worry, you're tired, go upstairs, take your bath and go to sleep'".

\section{Similarities between strategies adopted in Quebec} City and in Fortaleza. In both research sites, the effectiveness of individual or common strategies adopted by the partners varied according to (a) the partners' life context (e.g., periods of hard work or vacation), (b) the length of time for which these strategies were used, and (c) the partners' habituation to these strategies (i.e. being "used to" or "dependent on" strategies). The effects of the strategies on the partners' personal life or the couple's well-being were either neutral (no significant change), positive or negative, in the short as well as long term:

Couple 9 (Canada) - Woman: "...I sleep with earplugs, I had a room-mate once who returned from work around midnight and it woke me up, so this was something that I did to help me fall asleep, and I'm dependent now (laugh), I'm no longer able to sleep without them..."

Couple 6 (Brazil) - Woman: "There's no change if I go sleep in another room, in separate beds, I will probably still wake up at night, I will be thinking or worried..."

Finally, in Quebec City and Fortaleza, being active in the search or the adoption of strategies ensured neither the efficiency nor the satisfaction of the person who used them:

Couple 2 (Brazil) - Woman: "I'll be honest, I think of all the times l've tried several things [foot massage, warm milk, warm bath, watching TV], I can't say, you know, 'this really works for me!'... So, as a rule, today I prefer to stay in bed, I try to close my eyes and I try to empty my mind when that is possible. I see this calms me... me down in terms of anxiety, but to say, you know... 'I do this and I can sleep'... No, I can't confirm this as effective in combating insomnia" 
Intervention or drug use to cope with sleep difficulties. A minority of participants from Quebec City and Fortaleza reported sleeping in separate rooms or using licit drugs (e.g., alcohol, Diazepam, Alprazolam, Valeriane, Melatonin) to cope with their sleep difficulties. Globally, using drugs did not produce the expected effects, and a non-restorative sleep was the most commonly reported side effect:

Couple 3 (Brazil) - Man: "The Diazepam gives me that: I lie down and I'm off! I don't remember having a single dream! If I'm cold, or if I want to pee or anything else, simply... I don't wake up all night long and I wake up in the morning brand new!"

Couple 6 (Canada) - Woman: "I've tried natural products, such as Melatonin, to fall asleep more easily. It works more or less... I think I would need to take a powerful sleeping drug during two weeks to redo my sleep cycle, cause it seems that my cycle is stuck at 3-4h of sleep and that's it!"

Couple 4 (Brazil) - Man: "I've already used alcohol before going to bed... I would buy a bottle of whisky, I... slept quickly but, on the other hand, I would wake up early in the morning with headache, and a sensation of throwing up..."

In both research sites, the strategies based on pharmacological intervention, as well as the strategy of sleeping in separate rooms, were sometimes stigmatized by either or both partners. Stigmatization resulted from concerns about the potential addiction to alcohol or drugs and deterioration of health quality, and creation of a barrier in the couple's relationship. In this context, participants reported having open discussions in order to adjust these choices to their respective expectations, whilst taking into account the norms in their own city/ country.

Sleep-needs negotiation. Negotiation of sleep needs in the couple relationship was also a strategy considered in the context of cohabitation, sleep environment (e.g., bedside, noises, room lighting/ temperature) and bed sharing. Indeed, partners from both cities particularly privileged bed sharing, but perceived it differently. In Quebec City, bed sharing was viewed more as a challenge, while in Fortaleza, as a prolongation of the institution of marriage. In conclusion, a balance was sought between expectations, desires, and the social roles of each partner in the implementation of strategies to cope with sleep difficulties or their consequences in daily life:

Couple 13 (Canada) - Man: "Both of us prefer the same bedside. However, I think that the fact we are capable of abandoning our favorite bedside in a regular way, so the other can sleep on her/his favorite side, it's good! We are both capable to make concessions. It's not always easy... Sometimes, I would prefer to keep my side"

Couple 5 (Canada) - Women: "I cannot anticipate everything [to put on socks, to go to the bathroom before saying good-night in bed], but I surely try, we talk about it, we try to adopt strategies, well, in any case, bed sharing means compromising, trying to make the other feel good too. I don't think it's so easy to do it... I think it's a challenge"

Couple 6 (Brazil) - Man: "I like to have two pillows, one queen size blanket, and I have all of them when I sleep, and she respects that... Sharing our bed it's like the seal of the marriage, the symbol of the union of a couple"

\section{DISCUSSION}

The aim of this study was to explore the strategies used by Canadian and Brazilian couples with sleep difficulties, as well as the potential sociocultural variations related to these strategies. Six couples from Quebec City (Canada) and five couples from Fortaleza (Brazil) were interviewed. These interviews underwent a phenomenological analysis based on the Critical Phenomenological Method. Three modalities of strategies emerged from the CPM analysis: individual, common and shared, and common and independent.

In the present study, both males and females participants used individual strategies oriented toward their partner in order to facilitate his/her sleep or to avoid disturbing them. This is in contrast with the results of 
Venn (2007), who found that women made more efforts than men to cope with the sleep disturbances, especially those caused by snoring. This author's results revealed, for instance, that it is mostly the female partners who relocated, whether the source of the disturbance was their partner's snoring or their own. This apparent contradiction between the two studies could be explained by the distinctive social norms surrounding sleep problems and snoring. Indeed, sleep problems such as insomnia are likely to be viewed as a weakness incompatible with valued social stereotypes for men (e.g., power and dominance) (Payne, Swami, \& Stanistreet, 2008). Such perceptions could be especially strong in countries like Brazil where the distinction between male and female social roles is more marked. On the contrary, snoring is often perceived as an acceptable "male behaviour" to which the female partner has to adapt (Venn, 2007).

Results showed that sleep management was influenced by cultural variations between the two countries, namely, marital status and cultural values. Most couples from Quebec City were in common law relationships, while the couples from Fortaleza were all married. This is in accordance with the most popular type of romantic relationship in the adult population in the province of Quebec, Canada (i.e. common law relationship) (Institut de la Statistique du Québec [ISQ], 2012) and Brazil (i.e. marriage) (Costa, 2004, unpublished master's thesis). According to some authors (Laplante \& Flick, 2010; Le Bourdais \& Lapierre-Adamcyk, 2004), partners in common law relationships favor equality concerning their rights and tasks, while the institution of marriage is characterized by a complementarity of roles between husband and wife. Regarding cultural values, autonomy, equality, and harmony prevail in Quebec City, while embeddedness, mastery, and hierarchy are predominant in Fortaleza (Schwartz, 2009). Accordingly, in Quebec City, common and shared strategies oriented toward both partners' sleep were more prevalent than in Fortaleza. The partners sought fairness in their efforts, which reflect a stronger individualization process than in Fortaleza. Their personalized strategies to cope with sleep difficulties were more cooperative and focused on both partners' sleep needs. Partners wanted to maintain their autonomy and freedom, but also the couple's wellbeing during the night. Each partner expressed his/her own interests and individual characteristics in reaching toward common welfare in bed sharing, which was viewed more as a challenge. In comparison, for the couples from Fortaleza, individual strategies to cope with sleep difficulties were more prevalent. These strategies were focused on oneself or oriented toward the partner, indicating a greater specialization of tasks and complementarity of roles. Indeed, the partners tended to adopt an attitude of mutual understanding regarding their respective preferences, instead of trying to make compromises for both of them. Moreover, in Fortaleza, the romantic view of "being together" (including love with a factor of "religiosity") is more pronounced than in Quebec City. As a consequence, bed sharing was viewed more as a natural prolongation of the institution of marriage.

Apart from the cultural differences distinguishing Quebec City and Fortaleza, both cities share an important similarity: they are embedded in the $24 \mathrm{~h} / 7$ pace of life. In the $24 \mathrm{~h} / 7$ societies, two major processes define sleep health: a medicalization process and a « healthicization » process (Hislop \& Arber, 2003; Williams, 2005; Williams, Seale, Boden, Lowe, \& Steinberg, 2008). The first refers to the biomedical system as the purveyor of knowledge and power regarding sleep difficulties and sleep disorders, including a pharmaceutical industry that influences drug prescriptions. The second process concerns the transfer, to the individuals, of the moral responsibility to adopt a proper sleep hygiene in order to have a good sleep quality. In other words, the health-seeking journey of the patient is personalized.

In the present study, there was little evidence for a medicalization process in either country. In general, participants from Quebec City and Fortaleza did not use drugs (with or without prescription) to facilitate their sleep, and hesitated to consult a physician for their sleep difficulties. In fact, these participants feared an addiction to drugs, which they thought would affect their psychological and social wellbeing, including their couple relationship. When licit drugs (e.g., alcohol, Diazepam, 
Alprazolam, Valeriane, Melatonin) were used, the partners discussed this practice in order to adjust it to their expectations as a couple, while taking into account the norms of their city/country of origin. On the other hand, a "healthicization" process was observable in both countries. Indeed, the participants' empowerment toward their sleep quality was reflected by their "healthy" strategies, which could be related to their (overall) high educational level. In the $24 \mathrm{~h} / 7$ society, unlimited and constant access to anecdotic and scientific information permits easy identification of behaviours that can promote sleep quality.

\section{LIMITATIONS}

The results of this study should be interpreted in the light of some methodological limitations. While the couples from Quebec City were interviewed in a neutral place, those from Fortaleza expressed the desire to be interviewed at home. Using a neutral place for the interview prevented the researcher from collecting more environmental information that would have been useful in the results' analysis. Moreover, in Quebec City, the interviews took place in winter, which occurs at the same time as the summer season in Fortaleza. To some extent, this difference can influence the sources of sleep difficulties (e.g. hot air due to summer time vs dry air due to heating in winter time) and the strategies used (e.g. using a fan vs taking a hot bath). Finally, one could argue that the small sample size prevents the generalizability of the results. However, in this study, as in qualitative studies in general, generalizability was not a pursued objective (Creswell, 1998). Rather, the present study aimed to collect novel, meaningful, preliminary data that could be of use in the development of future researches, may they be quantitative, qualitative, or mixed.

\section{Implications for research and practice}

The literature reveals that insomnia treatments are almost exclusively delivered in individual/group settings (Koffel, Koffel, \& Gehrman, 2015; Trauer, Qian, Doyle, Rajaratnam, \& Cunnington, 2015) or in the form of selfhelp (Ho et al., 2015). On the contrary, for other mental disorders such as depression and post-traumatic stress disorder, a couple therapy has also been tested (Blow, Curtis, Wittenborn, \& Gorman, 2015; Wittenborn, Culpepper, \& Liu, 2012). Progression toward a "cognitive and behavioral couple therapy for insomnia" could contribute to (a) engage both partners in the evaluation and treatment of sleep problems; (b) develop new « common and shared » strategies and, by extension, (c) a greater openness to conscious discussion of sleep difficulties. In this regard, some common and shared strategies identified in this study, such as showing respect for the partner's sleep, could be adapted to sociocultural variations and used as therapeutic tools. Notably, improvement in marital satisfaction could, in turn, foster a reduction of insomnia severity (Troxel, Braithwaite, Sandberg, \& Holt-Lunstad, 2016).

Efforts to promote the integration of the partner into cognitive behavioral therapy for insomnia have already been undertaken. In their review, Rogojanski, Carney, and Monson (2013) propose ways for involving the partner during pre-treatment, treatment - psychoeducation, behavioral components, and cognitive components - and post treatment. Importantly, before new strategies are proposed to the partners, existing strategies should be considered and discussed. Indeed, the present study suggests that most couples already have a set of personalized strategies, some of which might be perpetuated during cognitive behavioral therapy for insomnia, while others might be abandoned.

\section{CONCLUSION}

Based on qualitative and quantitative data from 11 couples (six from Quebec City and five from Fortaleza), the present study reveals that the coping strategies used by Canadian and Brazilian partners are related not only to the individual, but can be shared. The participants use individual, common and shared or common and independent strategies to manage sleep difficulties of either or both partners. These strategies, including partners' beliefs and practices surrounding sleep, whether they origin in familial transmission or not, are closely related to the sociocultural (e.g., marital status, cultural 
values, $24 \mathrm{~h} / 7$ society), economic (e.g., educational level) and environmental (e.g., sleep environment) contexts of their respective countries. This is confirmed by the partners' compliance with the values, representations, rules, and norms established in each of their countries. Notably, in Quebec, the participants used more common and shared strategies oriented toward both partners, while in Fortaleza, they favored individual strategies focused on oneself or oriented toward the partner. In other words, couples from Quebec sought equity in their efforts to have a good night's sleep, which was a more individual-oriented choice in contrast to the Fortaleza couples, who were motivated to protect the partner's sleep. In the latter case, there was a concern for the partner's sleep, even to the point of accepting concessions, rather than a "justice" concern between partners. The partners' compliance with their cultural milieu, both in Quebec and in Fortaleza, was also highlighted by the use of personalized strategies focused on health, which reflected a « healthicization » process of sleep. In conclusion, additional cross-cultural studies are needed to highlight the ways in which sociocultural aspects can shape couples' sleep, since these aspects have a critical influence on the subjective experience of sleep (quality and quantity) of both partners.

Acknowledgment: None declared.

Conflicts of interest: The authors do not declare any conflict of interest.

Informed consent: Informed consent was obtained from all the participants included in the study.

Funding: The authors declare that the current study was not financially supported by any institution or organization.

\section{References}

Antoine, P., Christophe, V., \& Nandrino, J. (2008). Échelle d'ajustement dyadique: intérêts cliniques d'une révision et validation d'une version abrégée [Dyadic Adjustment Scale: Clinical interest of a revision and validation of an abbreviated form]. L'Encéphale, 34(1), 38-46.

Araújo, T., Jarrin, D. C., Leanza, Y., Vallières, A., \& Morin, C. M. (2017). Qualitative studies of insomnia: Current state of knowledge in the field. Sleep Medicine Reviews, 31, 58-69. doi:10.1016/j.smrv.2016.01.003

Arber, S., Meadows, R., \& Venn, S. (2012). Sleep and society. In C. M. Morin \& C. A. Espie (Eds.), The Oxford handbook of sleep disorders (pp. 223-247). New York, NY: Oxford University Press.

Bertolazi, A. N., Fagondes, S. C., Hoff, L. S., Dartora, E. G., da Silva Miozzo, I. C., de Barba, M. E. F., \& Barreto, S. S. M. (2011). Validation of the Brazilian Portuguese version of the Pittsburgh Sleep Quality Index. Sleep Medicine, 12(1), 70-75. doi:10.1016/j. sleep.2010.04.020

Blais, F., Gendron, L., Mimeault, V., \& Morin, C. M. (1997). Évaluation de l'insomnie: validation de trois questionnaire [Assessment of insomnia: Validation of three questionnaires]. L'Encéphale, 23(6), 447-453.

Blow, A. J., Curtis, A. F., Wittenborn, A. K., \& Gorman, L. (2015). Relationship problems and military related PTSD: The case for using emotionally focused therapy for couples. Contemporary Family Therapy, 37(3), 261-270. doi:10.1007/s10591-015-9345-7

Buysse, D. J., Reynolds, C. F., Monk, T. H., Berman, S. R., \& Kupfer, D. J. (1989). The Pittsburgh Sleep Quality Index: A new instrument for psychiatric practice and research. Psychiatry Research, 28(2), 193-213. doi:10.1016/0165-1781(89)90047-4

Creswell, J. W. (1998). Qualitative inquiry and research design: Choosing among five traditions. Thousand Oaks, CA: Sage Publications.
Elfström, M., Karlsson, S., Nilsen, P., Fridlund, B., Svanborg, E., \& Broström, A. (2012). Decisive situations affecting partners' support to continuous positive airway pressure-treated patients with obstructive sleep apnea syndrome: A critical incident technique analysis of the initial treatment phase. Journal of Cardiovascular Nursing, 27(3), 228-239. doi:10.1097/JCN.0b013e3182189c34

Ellis, J. G., Deary, V., \& Troxel, W. M. (2015). The role of perceived partner alliance on the efficacy of CBT-I: Preliminary findings from the Partner Alliance in Insomnia Research Study (PAIRS). Behavioral Sleep Medicine, 13(1), 64-72. doi:10.1080/15402002.2013.838768

Giorgi, A. (1985). Sketch of a psychological phenomenological method. In A. Giorgi (Ed.), Phenomenology and psychology research (pp. 8-22). Pittsburg, KS: Duquesne University Press.

Hernandez, J. A. E. (2008). Avaliação estrutural da escala de ajustamento diádico [Structural assessment of the dyadic adjustment scale]. Psicologia em Estudo, 13(3), 593-601.

Hislop, J. (2007). A bed of roses or a bed of thorns? Negotiating the couple relationship through sleep. Sociological Research Online, 12(5). doi:10.5153/sro.1621

Hislop, J., \& Arber, S. (2003). Understanding women's sleep management: Beyond medicalization-healthicization? Sociology of Health \& lllness, 25(7), 815-837. doi:10.1046/j.1467-9566.2003.00371.x

Ho, F. Y.-Y., Chung, K.-F., Yeung, W.-F., Ng, T. H., Kwan, K.-S., Yung, K.-P., \& Cheng, S. K. (2015). Self-help cognitive-behavioral therapy for insomnia: A meta-analysis of randomized controlled trials. Sleep Medicine Reviews, 19, 17-28. doi:10.1016/j.smrv.2014.06.010

Holliday, S. B., \& Troxel, W. (2017). Relationship quality: Implications for sleep quality and sleep disorders. In S. M. McHale, V. King, \& O. M. Buxton (Eds.), Family contexts of sleep and health across the life course (pp. 53-84). Switzerland: Springer. 
Institut de la Statistique du Québec. (2012). Le bilan démographique du Québec [The demographic profile of Quebec]. Retrieved from http://www.stat.gouv.qc.ca/ statistiques/population-demographie/bilan2012.pdf

Koffel, E. A., Koffel, J. B., \& Gehrman, P. R. (2015). A meta-analysis of group cognitive behavioral therapy for insomnia. Sleep Medicine Reviews, 19, 6-16. doi:10.1016/j.smrv.2014.05.001

Lalley-Chareczko, L., Segal, A., Perlis, M. L., Nowakowski, S., Tal, J. Z., \& Grandner, M. A. (2015). Sleep disturbance partially mediates the relationship between intimate partner violence and physical/ mental health in women and men. Journal of Interpersonal Violence, 32(16), 2471-2495. doi:10.1177/0886260515592651

Laplante, B., \& Flick, C. (2010). Le mariage, l'union de fait et la santé des conjoints au Québec et en Ontario [Marriage, common law union and partners' health in Quebec and Ontario]. Cahiers québécois de démographie, 39(1), 1-26.

Le Bourdais, C., \& Lapierre-Adamcyk, É. (2004). Changes in conjugal life in Canada: Is cohabitation progressively replacing marriage? Journal of Marriage and Family, 66(4), 929-942. doi:10.1111/j.0022-2445.2004.00063.x

Luyster, F. S., Strollo Jr, P. J., Zee, P. C., \& Walsh, J. K. (2012). Sleep: A health imperative. Sleep, 35(6), 727-734. doi:10.5665/ sleep.1846

Marshall, C., \& Rossman, G. B. (2016). Designing qualitative research, 6th edition. Los Angeles, CA: SAGE Publications.

Martin, P. (2005). Counting sheep: The science and pleasures of sleep and dreams. London: HarperCollins.

Moreira, V. (2004). O método fenomenológico de Merleau-Ponty como feramenta crítica na pesquisa em psicopatologia [MerleauPonty's phenomenological method as a critical tool to the research on Psychopathology]. Psicologia: Reflexão e Crítica, 17(3), 447-456. doi:10.1590/S0102-79722004000300016

Morin, C. M., \& Jarrin, D. C. (2013). Epidemiology of insomnia: Prevalence, course, risk factors, and public health burden. Sleep Medicine Clinics, 8(3), 281-297. doi:10.1016/j. jsmc.2013.05.002

National Sleep Foundation. (2010). 2010 sleep in America Poll: Summary of findings. Retrieved from https://sleepfoundation. org/

Payne, S., Swami, V., \& Stanistreet, D. L. (2008). The social construction of gender and its influence on suicide: A review of the literature. Journal of Men's Health, 5(1), 23-35. doi:10.1016/j.jomh.2007.11.002

Reishtein, J. L., Pack, A. I., Maislin, G., Dinges, D. F., Bloxham, T. J., George, C. F. P., . . . Weaver, T. E. (2006). Sleepiness and relationships in obstructive sleep apnea. Issues in Mental Health Nursing, 27(3), 319-330. doi:10.1080/01612840500503047

Rogojanski, J., Carney, C. E., \& Monson, C. M. (2013). Interpersonal factors in insomnia: A model for integrating bed partners into cognitive behavioral therapy for insomnia. Sleep Medicine Reviews, 17(1), 55-64. doi:10.1016/j.smrv.2012.02.003
Rosekind, M. R., \& Gregory, K. B. (2010). Insomnia risks and costs: Health, safety, and quality of life. The American Journal of Managed Care, 16(8), 617-626.

Rosenblatt, P. (2006). Two in a bed: The social system of couples bed sharing. New York, NY: State University of New York Press.

Schwartz, S. H. (2009). Culture matters: National value cultures, sources, and consequences. In R. S. Wyer, C.-y. Chiu, \& Y.-y. Hong (Eds.), Understanding culture: Theory, research, and application (pp. 127-150). New York, NY: Psychology Press.

Spanier, G. B. (1976). Measuring adjustment: New scales for assessing the quality of marriage and similar dyads. Journal of Marriage and Family, 38(1), 15-28. doi:10.2307/350547

Trauer, J. M., Qian, M. Y., Doyle, J. S., Rajaratnam, S. M. W., \& Cunnington, D. (2015). Cognitive behavioral therapy for chronic insomnia: A systematic review and meta-analysis. Annals of Internal Medicine, 163(3), 191-205. doi:10.7326/m142841

Troxel, W. M., Braithwaite, S. R., Sandberg, J. G., \& Holt-Lunstad, J. (2016). Does improving marital quality improve sleep? Results from a marital therapy trial. Behavioral Sleep Medicine, 15(4), 1-14. doi:10.1080/15402002.2015.1133420

Troxel, W. M., Buysse, D. J., Hall, M., \& Matthews, K. A. (2009). Marital happiness and sleep disturbances in a multi-ethnic sample of middle-aged women. Behavioral Sleep Medicine, 7(1), 2-19. doi:10.1080/15402000802577736

Troxel, W. M., Robles, T. F., Hall, M., \& Buysse, D. J. (2007). Marital quality and the marital bed: Examining the covariation between relationship quality and sleep. Sleep Medicine Reviews, 11(5), 389-404. doi:10.1016/j.smrv.2007.05.002

Venn, S. (2007). "It's okay for a man to snore": The influence of gender on sleep disruption in couples. Sociological Research Online, 12(5). doi:10.5153/sro.1607

Venn, S., Arber, S., Meadows, R., \& Hislop, J. (2008). The fourth shift: Exploring the gendered nature of sleep disruption among couples with children. British Journal of Sociology, 59(1), 7998. doi:10.1111/j.1468-4446.2007.00183.x

Vercelli, L. (2006). Versões de sentido: um instrumento metodológico [Sense's versions: A methodological tool]. Cadernos de Pós-Graduação, 5(1), 191-196.

Williams, S. J. (2005). Sleep and society: Sociological ventures into the (un)known. London, UK: Routledge.

Williams, S. J., Coveney, C. M., \& Gabe, J. (2013). Medicalisation or customization? Sleep, enterprise and enhancement in the 24/7 society. Social Science \& Medicine, 79, 40-47.

Williams, S. J., Seale, C., Boden, S., Lowe, P., \& Steinberg, D. L. (2008). Medicalization and beyond: The social construction of insomnia and snoring in the news. Health, 12(2), 251-268. doi:10.1177/1363459307086846

Wittenborn, A. K., Culpepper, B., \& Liu, T. (2012). Treating depression in men: The role of emotionally focused couple therapy. Contemporary Family Therapy, 34(1), 89-103. doi:10.1007/s10591-012-9176-8 